REVESCO. Revista de Estudios Cooperativos

ISSN: $1885-8031$

\title{
Cooperativas de ahorro y crédito en Ecuador: el desafío de ser cooperativas
}

\author{
Arturo Luque González ${ }^{1}$ y Jacqueline Peñaherrera Melo $^{2}$
}

Recibido: 10 de junio de 2020 / Aceptado: 12 de enero de 2021 / Publicado: 8 de abril de 2021

Resumen. En la República de Ecuador, el sistema financiero vigente se compone de instituciones públicas y privadas, así como de procesos de economía popular y solidaria mostrando con ello un claro elemento diferenciador. Todas estas entidades son regidas por una misma normativa en función de su actividad de intermediación financiera. De ahí la necesidad de analizar el sistema financiero vigente y sus fines tanto en el sistema bancario, así como en las cooperativas de ahorro y crédito. Con esta finalidad se elabora su taxonomía de incoherencias como resultado de la aplicación de regulaciones similares a pesar de que su origen y objeto social son conceptualmente diferentes. Para ello se realiza un análisis de la información existente de carácter público, en el segmento de cooperativas de ahorro y crédito de mayor tamaño conforme a sus activos, en relación a la necesidad de generar valor agregado en la aplicación de los procesos de responsabilidad social cooperativa bajo principios de solidaridad y ética en empresas del sector asociativo de propiedad común. Se evidencia que el compromiso social afecta a los resultados financieros, pero a su vez, mejora la gestión en la búsqueda incesante del bienestar común de socios, entorno natural y sociedad.

Palabras clave: Economía popular y solidaria; Sector asociativo; Cooperativas de ahorro y crédito; Ecuador; Economía social.

Claves Econlit: R11; A13; B55; M14; P13.

\section{[en] Savings and credit cooperatives in Ecuador: the challenge of being cooperatives}

\begin{abstract}
In the Republic of Ecuador, the current financial system consists of public and private institutions, as well as processes of popular and solidarity economy, showing a clear differentiating element. All these policies are governed by the same regulations based on their financial intermediation activity. Hence the need to analyze the current financial system and its purposes both in the banking system, as well as in the savings and credit cooperatives sector. For this purpose, its taxonomy of inconsistencies is elaborated as a result of the application of similar regulations despite the fact that its origin and corporate purpose are conceptually different. For this, an analysis of the existing information is carried out in the segment of the largest credit cooperatives sector to their assets, in relation to the need to generate added value in the application of responsibility processes social cooperative under principles of solidarity and ethics in companies of the associative sector of common property. It is evident that social commitment affects financial results, but in turn, improves management in the incessant search for the common well-being of partners, natural environment and society.
\end{abstract}

Keywords: Popular and solidary economy; Associative sector; Cooperatives of saving and credit; Ecuador; Social economy.

Sumario. 1. Introducción. 2. Sector cooperativo, sistema económico en Ecuador y responsabilidad social. 3. Abordaje del problema. 4. Análisis y resultados. 5. Consideraciones finales. 6. Referencias bibliográficas. 7. Anexos.

Cómo citar. Luque González, A.; Peñaherrera Melo, J. (2021) Cooperativas de ahorro y crédito en Ecuador: el desafío de ser cooperativas. REVESCO. Revista de Estudios Cooperativos, vol. 138, e73870. https://dx.doi.org/10.5209/reve.73870.

\section{Introducción}

La génesis actual en las organizaciones de trabajadores se relaciona con momentos sociológicos de gran relevancia. Estos pueden resumirse en los siguientes: parlamentario y constitucional, dirigidos contra la oligarquía; agrario, relacionado con mejoras en la agricultura a través de reformas agrarias y críticorevolucionario dirigido por los intelectuales ingleses y los artesanos londinenses en la Revolución Francesa (Lucas, García y Llano, 2002). Tales circunstancias ocasionaron cambios económicos los cuales provocaron

1 Universidad Técnica de Manabí, Portoviejo, Ecuador y Universidad del Rosario, Bogotá, Colombia.

Dirección de correo electrónico: arturo.luque@utm.edu.ec.

2 Universidad Rey Juan Carlos, Madrid, España.

Dirección de correo electrónico: jacquipm@gmail.com. 
importantes transformaciones en la sociedad, en la mentalidad de los individuos y en la organización política; aun así, seguían existiendo diferencias sociales y económicas que el lógico paso del tiempo y la tecnología no se lograron resolver (Fernández, 2012). Esta realidad, provocó la crítica de pensadores como Robert Owen, quien después de estudiar la historia de la humanidad concluyó que el hombre es el resultado necesario de su organización y de las condiciones en que le sitúan la naturaleza y la sociedad (UNESCO, 2018). Este paradigma se convirtió junto con la teoría del contrato social y político, en el fundamento de una sociedad cuyos miembros eran, aparentemente libres e iguales. Se impulsó también por los llamados reformadores y más tarde por los comunistas y socialistas, los mismos que se reconocen como los antecesores del cooperativismo (Chauveau, Alderete, Carrasco, Hernández y Linsambarth, 2010). A partir de ahí la necesidad de articular procesos sociales y herramientas económicas y financieras pasa de la realidad a los hechos.

El surgimiento de las organizaciones empresariales asociativas o cooperativas no era tan novedoso como práctica, pero sí a nivel conceptual, por ello se relaciona frecuentemente con situaciones de pobreza en regiones deprimidas asociadas en muchas ocasiones a lugares como América Latina, Asia y África. También se relacionan con grupos sociales localizados en países industriales los cuales se encuentran marginados del bienestar general y tratan de salir adelante mediante estas empresas democráticas aun teniendo a buena parte de la legislación transnacional en contra, pues favorece el libre comercio de carácter ilimitado comprometiendo en ocasiones el interés general (Passet, 2013). Estas experiencias económicas participativas responden a tradiciones autóctonas, a procesos económicos y políticos o a la combinación de los mismos (Coque, 2005). En ocasiones las acepciones de estas organizaciones terminan inevitablemente coaligadas a la pobreza y la marginación o calificadas de antisistema. También existen otras posiciones de carácter más ortodoxo y utilitarista al respecto (Evans y Syrett, 2007; Moulaert y Ailenei, 2005). Las organizaciones vinculadas con el sector de la economía social y solidaria (ESS) principalmente son asociaciones, cooperativas, fundaciones, empresas sociales, mutuas, banca solidaria, banca ética y emprendimientos sociales, todas ellas constituidas en base a un modelo alternativo a la economía de mercado. Se establecen bajo la doctrina de la asociatividad y del cooperativismo para precautelar el bienestar de sus socios (Coraggio, 2013; Birchall, 2004). En este contexto, la Alianza Cooperativa Internacional -ACI-, define a las cooperativas como empresas centradas en las personas, de propiedad compartida, que son controladas y dirigidas por sus asociados y que aparecen con el fin de responder a necesidades y aspiraciones comunes, muchas de éstas se generan para suplir la falta de acceso a un trabajo que proporcione a las familias bienestar (Alianza Cooperativa Internacional, 2018). El Consejo Mundial de Cooperativas de Ahorro y Crédito COAC- (WOCCU, por sus siglas en inglés) las define como "cooperativas financieras democráticas propiedad de los socios". Como intermediarias financieras, las cooperativas de ahorro y crédito financian sus carteras de créditos movilizando los ahorros de los socios y los depósitos más que empleando capital externo" (Organización de las Naciones Unidas para la Alimentación y la Agricultura - FAO, 2019), de manera que las cooperativas de ahorro y crédito existen para atender a sus socios y comunidades. Como instituciones cooperativas sin fines de lucro, las cooperativas de ahorro y crédito emplean sus ingresos excedentes para ofrecer a los socios créditos más accesibles, un mayor rendimiento sobre sus ahorros, comisiones más bajas o nuevos productos y servicios. Atienden a los socios de todos los niveles socioeconómicos, incluyendo los pobres, a todos aquéllos privados de derechos y en definitiva a muchas personas expulsadas del sistema. En la actualidad la participación del saldo de la cartera por tipo de crédito en el sector financiero y popular y solidario en Ecuador se divide en un $51 \%$ de consumo, $36 \%$ microcrédito, $10 \%$ vivienda y un $3 \%$ de carácter comercial evidenciando su concentración en los dos primeros; al igual que en otros países de América Latina, existe una larga y constante relación con los sistemas cooperativos. Estas relaciones se registran incluso antes de la conquista de los incas en formas de organización de la sociedad donde se prioriza el bien común a través de mingas y trabajo comunitario propio de los pueblos indígenas -en muchos casos se mantiene hasta la actualidad-. Además, en estos países el cooperativismo es un fenómeno comunitarista de alta implantación y capilaridad (Guerra, 2014).

\section{Sector cooperativo, sistema económico en Ecuador y responsabilidad social}

En 1927 se registra la primera cooperativa de ahorro y crédito en Ecuador. Ya en 1959 existían 61 de ellas, número que se multiplicó a gran velocidad en la siguiente década, y en 1969 el número ascendió a 480. De acuerdo a los registros de los organismos de control, el mayor número de cooperativas financieras aparecen en el catastro de 2013, con un total de 947. Al finalizar 2016, la Superintendencia de Economía Popular y Solidaria -SEPS- oficializó que las cooperativas eran 740, como consecuencia de las políticas de supervisión implementadas (da Ros, 2007; Jácome, 2016). En la actualidad, la economía popular y solidaria en el país concentra a más de 5 millones de asociados, de los cuales, el $28.03 \%$ son mujeres vinculadas al sector y el $21.75 \%$ es población joven. En cuanto a los activos que posee el sector financiero popular y solidario estos rebasan los 16 mil millones de dólares, que equivalen al 15\% del PIB en Ecuador. De ellas, el 32\% de las 
organizaciones de la EPS pertenecen al sector agropecuario, uno de los mayores generadores de empleo en el país, pues cuenta con el $29.4 \%$ de los trabajadores vinculados (SEPS, 2020).

La primera Ley de Cooperativas se registra en Ecuador como intervención del Estado en 1937. Aquí se menciona a la Caja de Ahorro y Cooperativa de Préstamos de la Federación Obrera de Chimborazo como la primera organización financiera en 1927. En su análisis se hace un registro de cómo el número de instituciones de ahorro y crédito evolucionan, junto a datos de la Superintendencia de Economía Popular y Solidaria con el fin de contar con una visión actual de la situación cooperativa financiera del país (Jácome, 2019). El decremento de cooperativas entre 2013 y 2016 se debe a la aplicación de la regulación vigente en el país que en la actualidad las clasifica en base a segmentos. Estos se articulan de acuerdo a su participación en el sector, volumen de operaciones que desarrollen, número de socios, número y ubicación geográfica de oficinas, montante de activos, patrimonio, productos y servicios financieros ofrecidos tal como se muestra en la Tabla 1.

Tabla. 1. Clasificación

\begin{tabular}{lcl}
\hline & \multicolumn{2}{c}{ SEGMENTACIÓN DE COOPERATIVAS DE AHORRO Y CRÉDITO EN ECUADOR } \\
\hline SEGMENTOS & COAC & \multicolumn{1}{c}{ ACTIVOS (USD) } \\
Segmento 1 & 32 & Mayor a 80.000 .000 \\
Segmento 2 & 40 & Mayor a 20.000 .000 hasta 80.000 .000 \\
Segmento 3 & 79 & Mayor a 5.000.000,00 hasta 20.000 .000 \\
Segmento 4 & 174 & Mayor a $1.000 .000,00$ hasta 5.000.000 \\
Segmento 5 & 258 & Hasta 1.000.000 \\
\hline Total: & $\mathbf{5 8 3}$ &
\end{tabular}

Fuente: elaboración propia a partir del Catastro de Cooperativas (Superintendencia de Economía Popular y Solidaria, 2019)

Desde 2018, las cooperativas son clasificadas según los montos en activos. En el caso del segmento 1, son 30 de acuerdo a las publicaciones de balances mensuales que realiza la Superintendencia de Economía Popular y Solidaria (ver Anexo 1). De éstas, 5 son entidades indígenas de las cuales 3 se ubican en la provincia de Tunguahura. Las COAC indígenas representan el 7,8\% de los activos del total del segmento. En la provincia de Tungurahua se cuenta además con Oscus, San Francisco, El Sagrario y Cámara de Comercio de Ambato; por tanto, el monto total en activos representa el 15,97 \% del sistema cooperativo del segmento 1 en Ecuador, ocupando el tercer lugar después de Azuay y Pichincha. Entre las cooperativas, destaca Juventud Ecuatoriana Progresista Ltda. - JEP, que representa más del 20\% del segmento en Ecuador y Jardín Azuayo cuya participación en el mercado es de 9,04\%. Ambas cooperativas tienen su matriz en la ciudad de Cuenca (zona Austral), con presencia nacional a través de agencias y cajeros (ATM).

Gráfico. 1. Relación entre las primera y segunda Institución Financiera - IFI

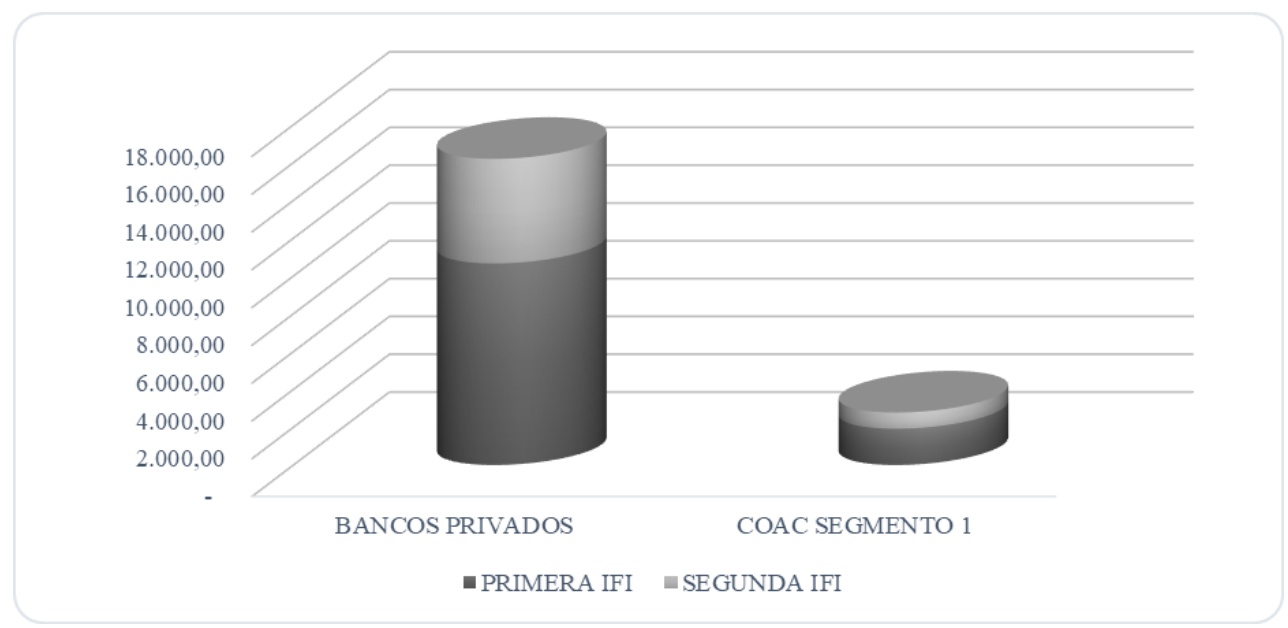

Fuente: elaboración propia a partir de los Anexos 1 y 2 
Por otro lado, los datos del sector bancario privado -BP- en total ascienden a 24 entidades (ver Anexo 2). En referencia al tamaño en activos, se aprecia que el Banco del Pichincha es el de mayor envergadura con 27,24\% del total de sistema y que su participación duplica al siguiente que es el Banco del Pacífico representando el 13,99\% de la banca privada. Estas instituciones financieras nacen en Quito y en Guayaquil, respectivamente, pero tienen presencia nacional. La relación entre la primera y segunda posición de las instituciones financieras en relación a sus activos (en millones de dólares), tanto entre las COAC y como entre los BP, se presenta en el Gráfico 1.

Según el registro que se presenta en los Anexos 1 y 2, el sistema Financiero Cooperativo en Ecuador representa el 18,82\% de los activos totales del sistema financiero ecuatoriano en 2018 y se rige de acuerdo a la misma legislación, el Código Orgánico Monetario. Por tanto, sus balances y estados financieros se ajustan a un mismo catálogo único de cuentas, pese a estar regentados por organismos de control diferentes ${ }^{3}$. En estas circunstancias, las cooperativas de ahorro crédito se enfrentan a un gran dilema. Por la naturaleza de su servicio, son reguladas y actúan como un banco, pero de acuerdo a su conformación y filosofía de gestión deben mantener indicadores sociales que den cuenta y respondan al modelo asociativo. El estudio de sus balances muestra una marcada preocupación por sus rendimientos financieros, dejando como un factor de cumplimiento obligatorio y accesorio el tratamiento de los indicadores sociales y de solidaridad (Luque, Peñaherrera y Ordoñez, 2019).

A partir de lo anteriormente descrito en el presente trabajo, 1) se analiza la taxonomía de incoherencias existente donde tanto las COAC así como el sistema bancario tradicional tienen similitud a la hora de cumplir determinados requerimientos a pesar de tener una idiosincrasia diferente, 2) se examina la concentración del mercado a partir del Indice de Herfindahl Hirschman y 3) se determina de manera comparada a partir de nueve indicadores la relación entre COAC y BP en un periodo de cuatro años (Anexo $3)$.

\subsection{Sistema económico en Ecuador}

En los últimos 20 años, Ecuador ha tenido dos cartas constitucionales; en ellas se definió el sistema económico que debía implementarse a través de la intervención del Estado (Luque y Casado, 2020). En el Gráfico 2, se representa la diferencia entre la economía social de mercado y la economía social y solidaria contenidas en las Constituciones 1998 y 2008 respectivamente. Los cambios políticos en Ecuador en el año 2007 marcaron una evidente necesidad de cambio en el sistema económico (Martín-Mayoral, 2009); de hecho, parte del programa económico del gobierno de entonces (2007-2017) pivotaba sobre esa premisa. La visión de abandonar la desregulación absoluta del modelo económico heredado en favor de otra forma de económica más social involucraba giros profundos. No solo se trataba de desplazar el control o las decisiones de un grupo hegemónico a otro, se trataba de afrontar transformaciones de fondo pasando de una economía centrada en la acumulación y la tiranía del mercado hacia una orientada a la sostenibilidad de la vida, la justicia y la democracia bajo el concepto ancestral del Buen Vivir (Harvey, 2007; Acosta, 2010, Solón, 2020). En la búsqueda de un modelo alternativo, que sustituyera a la llamada economía social de mercado (de la Constitución de 1998), la economía social y solidaria apareció con esos alcances paradigmáticos, apenas como un sector más y en ocasiones como un conjunto de experiencias asociativas presentes históricamente en el país (León, 2009).

En la economía de mercado, las decisiones del planificador central son sustituidas por las de estratégicos centros de decisión transnacional, organismos supranacionales junto a millones de empresas y hogares. Las empresas deciden a quien contratar y qué producir apoyadas por una legislación favorable, mientras que determinadas familias deciden -cada vez menos- en qué empresas trabajar y a quien comprar mediante sus rentas generadas (Mankiw y Taylor, 2017). En este contexto se desarrolló la economía de Ecuador entre los años 1998 y 2008, época que la empresa privada lideraba el mercado y todos sus resortes institucionales en virtud de la libertad del manejo de recursos que les confería la legislación y quedando subsumida a las prácticas dominantes existentes a nivel global. En la década en que el sistema económico de Ecuador era de economía social de mercado -con premisas basadas en competencia, libre mercado, descentralización y explotación de mercado (Gráfico 2)- los organismos de control mostraban criterios de flexibilidad. Algo coherente con el modelo de la época al ser en teoría un sistema de libre mercado completamente desregulado el cual permitía la existencia de un régimen político democrático vehiculado a través del poder del mercado y sus elementos consustanciales de carácter exógeno. Con ello, en ocasiones se apostataba de funciones políticas regulatorias en favor del propio mercado y sus elementos irradiadores como única herramienta de control. Es decir, como señala Sánchez Barrilao (2004), el estado legisla no legislando.

En la actualidad, tal circunstancia tiene sus incoherencias, así como limitaciones. De hecho, la legislación laboral, financiera y tributaria termina siendo decisoria e intervencionista incluso en sistemas de liberalismo

Superintendencia de Economía Popular y Solidaria, controla las cooperativas de ahorro y crédito. Superintendencia de Bancos, controla a los bancos privados. 
de mercado (Polo-Blanco, 2019) aunque sus intereses no dejen de estar alineados de manera particular con el gran capital transnacional y sus elementos facilitadores que elevan el derecho al comercio como derecho fundamental conocido como lex mercatoria (Hernández Zubizarreta y Ramino, 2016).

Gráfico. 2. Sistema económico de Ecuador.

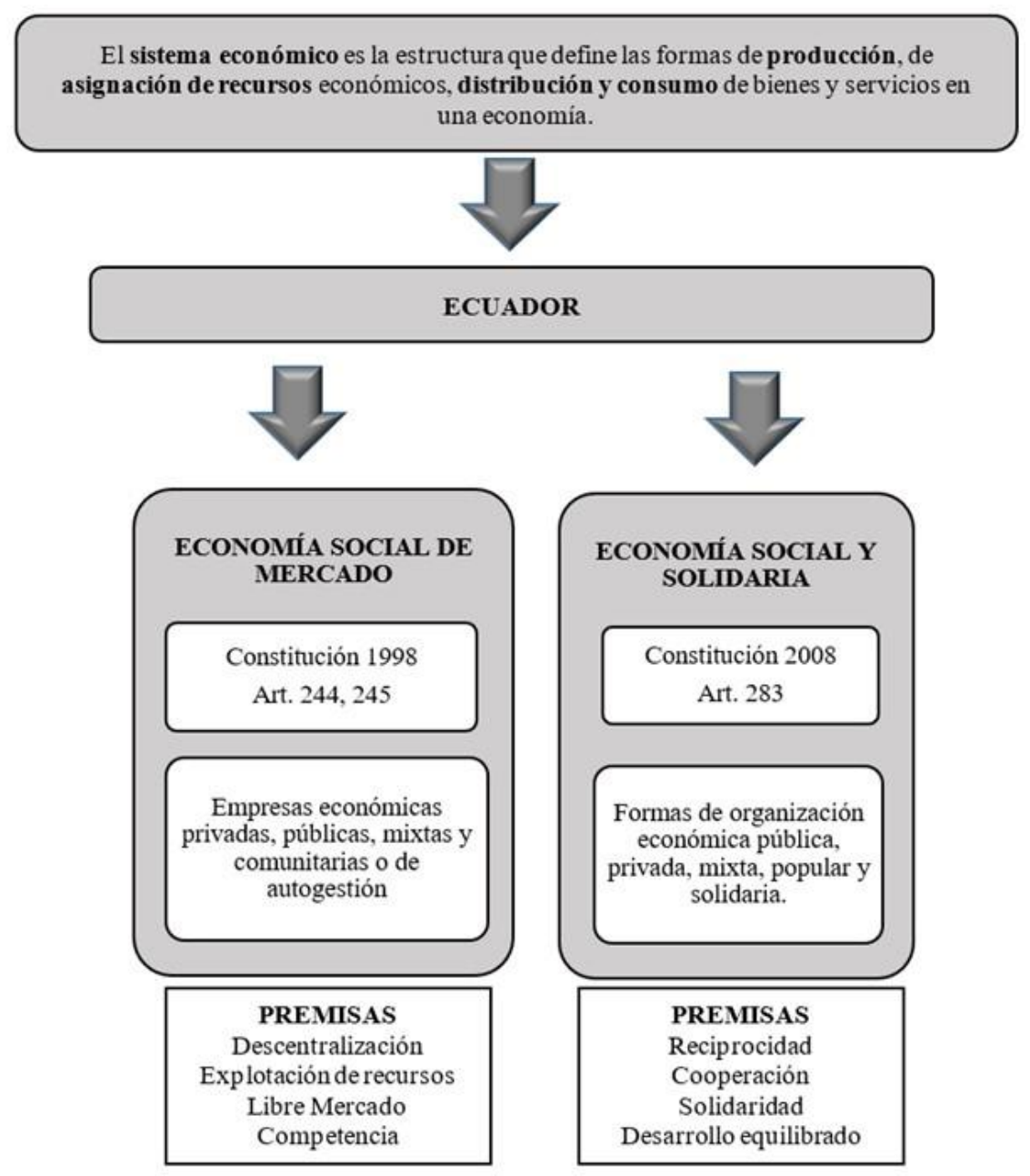

Fuente: elaboración propia a partir de Constitución 1998 (Asamblea Constituyente, 1998) y Constitución 2008 (Asamblea Constituyente, 2008)

Con la Constitución del año 2008, el sistema económico adoptado en Ecuador se establece como social y solidario. Con esto se reconoce al ser humano como sujeto y fin además de establecer especial protección al entorno natural; en muchos casos esta protección queda pervertida debido a los procesos de extractivismo y dependencia continua a los que a partir de ese periodo se someten todos sus recursos naturales a pesar de existir un texto constitucional que ordena lo contrario como era la Constitución de Montecristi 2008 (Luque, Herrero-García y Peñaherrera, 2018). Aun así, se promueve una relación dinámica y equilibrada entre sociedad, Estado y mercado, en armonía con la naturaleza y se garantiza la producción y reproducción de las condiciones materiales e inmateriales que posibiliten el buen vivir, sistema que se ampara en las premisas de reciprocidad, cooperación, solidaridad, complementariedad y de desarrollo equilibrado (Gráfico 2). En el año 2015, Elizondo define la Economía Social y Solidaria como el conjunto de recursos y actividades de cualquier organización que funcione de acuerdo a los principios de la solidaridad para desarrollar actividades de producción, distribución, circulación, financiamiento y consumo en condiciones de dignidad y responsabilidad, de forma que se garantice sus bases materiales y sus relaciones sociales y con la naturaleza, también conocida como economía social, social y solidaria, popular y solidaria, de las empresas sociales o sin fines de lucro (Guridi y Jubeto, 2014). En Latinoamérica la ESS es considerada como un fenómeno comunitarista que impulsa la concepción de una sociedad alejada de los paradigmas individualistas y totalitarios en base al pensamiento y a las prácticas de las comunidades (Guerra, 2014). Un caso evidente de la fusión de lo comunitario con lo asociativo son las cooperativas financieras indígenas en Ecuador o las asociaciones campesinas en Bolivia. Muchas de ellas no solo giran en torno a las tradiciones sino además a la religión de las comunidades de donde son sus fundadores. En la actualidad, aún se discute ampliamente 
sobre cómo la economía puede encargarse del estudio de estas formas de organización. En este contexto, la Economía Social (ESoc) da cabida a una serie de organizaciones socio-económicas las cuales establecen una forma de convivencia entre las personas y la naturaleza que satisface las necesidades humanas, mientras que la Economía Solidaria (ESol) emana criterios para el aprendizaje a través de proyectos asentados en el bien común de manera desinteresada, de tal forma que la convergencia teórica de ambos términos dan paso a la Economía Social y Solidaria (ESS) (Pérez de Mendiguren y Etxezarreta, 2015). De acuerdo con Razzeto (2006) "la economía solidaria o economía de solidaridad es una búsqueda teórica y práctica de formas alternativas de hacer economía, basadas en la solidaridad y el trabajo". Es decir, el ser humano se convierte en el vértice de las relaciones económicas y humanas siendo el mercado una herramienta más a su servicio que puede ser utilizada o no. En cualquier caso, eximiendo al mercado de ostentar carácter sacrosanto no utilizándose ni de manera exclusiva ni excluyente.

En Ecuador, como queda evidenciado, se reconoce a las empresas públicas, privadas y mixtas como parte de la economía popular y solidaria incluyendo a su vez a los sectores cooperativos, asociativos y comunitarios. Sin embargo, a pesar de la plena vigencia de la Constitución de 2008, no todos los sectores han evidenciado una gestión recíproca, solidaria o de desarrollo equilibrado. Esto, en parte es debido al excesivo control ejercido por el Estado que además se ha centrado en mostrar el nuevo sistema casi exclusivamente hacia las organizaciones de la Economía Popular y Solidaria.

\subsection{Sistema financiero en Ecuador}

El sistema financiero se define como el conjunto de activos y pasivos, considerado productos financieros los que son emitidos u ofertados por las instituciones financieras a través de mecanismos de mercado geográfico o virtual y que son adquiridos por personas, empresas o instituciones con capacidad de pago (Estévez-Torres y Clivillé, 2019). En Ecuador, el sistema financiero está integrado por tres elementos esenciales: las leyes que regulan la actividad financiera, los órganos rectores y las instituciones de servicios financieros. El Código Orgánico Monetario y Financiero del año 2014 (con el fin de regular los sistemas monetarios y financieros de Ecuador) reemplazó a la Ley General de Instituciones del Sistema Financiero emitida en el año 1994 y se constituye en la principal regulación financiera del país.

En términos generales, el Código Orgánico Monetario y Financiero establece el marco de políticas, regulaciones, supervisión, control y rendición de cuentas que rige los sistemas monetario y financiero, y concentra la emisión de la política monetaria en un solo ente designado Junta de Política y Regulación Monetaria y Financiera que será responsable de la declaración de las políticas públicas, además de la regulación y supervisión monetaria, crediticia, cambiaria, financiera y de seguros. El Código define a la actividad financiera como "el conjunto de operaciones y servicios que se efectúan entre oferentes, demandantes y usuarios, para facilitar la circulación de dinero y realizar intermediación financiera" (Asamblea Nacional de Ecuador, 2014). Atendiendo a este marco legal, los órganos rectores directos del sistema financiero de Ecuador, son:

1. La Superintendencia de Bancos del Ecuador -SBS- que, junto con el Banco Central de Ecuador, se encarga de la aplicación de las directrices que desde el Ministerio Coordinador de la Política Económica, y el Ministerio de Finanzas para conservar un correcto nivel de liquidez y estabilidad en el Sistema. Ofrecen información vigente, profunda y competente de las instituciones financieras públicas y privadas a los beneficiarios del sistema para facilitar sus disposiciones al momento de pactar o adquirir los productos y servicios financieros. El Código Monetario en sus artículos 161 y 162, estable la composición del sector financiero público y privado respectivamente. Entre lo público se consideran a los bancos y corporaciones. En lo privado constan: bancos múltiples y especializados, entidades de servicios financieros y entidades de servicios auxiliares.

2. La Superintendencia de Economía Popular y Solidaria, creada en 2012 con el fin de regular de forma especializada a las organizaciones de la economía popular y solidaria, del sector financiero y no financiero. En el marco del sistema financiero de Ecuador, ejerce las funciones de vigilancia, auditoría, control y supervisión de las instituciones del sector financiero popular y solidario, compuesto por cooperativas de ahorro y crédito, cajas centrales, entidades asociativas y asociaciones mutualistas de ahorro y crédito para la vivienda.

\subsection{Responsabilidad social en la intermediación financiera con identidad cooperativa}

Las organizaciones, como parte de una sociedad dinámica y en constante cambio, también están obligadas a cambiar (Bauman y Bordoni, 2016). Las transformaciones económicas actuales deben promover su adaptación a los cambios sociales y medioambientales existentes (Mathiyazhagan, Govindan, NoorulHaq y Geng, 2013). Las organizaciones deben estar contextualizadas en relación a las necesidades de las comunidades sociales (Schlusberg, 1969) con la finalidad de mejorar la sociedad con la cual se interrelacionan (Fernández, Geba, Montes y Schaposnik, 1998). No es diferente para las cooperativas de 
ahorro y crédito que además deben desarrollarse en referencia a varios marcos legales; el primero en función de las leyes (contrato formal); el segundo determinado por un contrato semi formal basado por la adopción voluntaria de normas internacionales; y un tercero caracterizado por las coyunturas sociales, políticas, económicas que determinan expectativas sociales que pueden afectar de manera sustancial su actividad y lo que se conoce como asuntos emergentes (Asociación Nacional de Cooperativas de Ahorro y Crédito controladas por la SBS, 2010).

Las cooperativas deben promover el clima necesario para la vinculación entre empresas, sindicatos y Estado con el fin de coexistir de manera dinámica e integradora con todos los grupos de interés con los que interactúan ejerciendo un claro papel protagonista dentro de su dimensión social y medioambiental (Lucena, Freitez y Hernández, 2007). Ser responsable como organización es consustancial a los orígenes cooperativos, forma parte de su misión, de su idiosincrasia debiéndose proyectar como medio y no como fin (BastidasDelgado, 2007). Además, contribuyen de manera sólida a promover procesos de sostenibilidad (Loor et al., 2020) a pesar del creciente aumento a nivel global de conductas irresponsables (Luque y Herrero-García, 2019).

Tabla. 2. Conceptos

\begin{tabular}{|c|c|}
\hline & COOPERATIVAS Y COOPERATIVAS DE AHORRO Y CRÉDITO \\
\hline $\begin{array}{l}\text { Cooperativa según } \\
\text { ACI }\end{array}$ & Cooperativa de Ahorro y Crédito según WOCCU \\
\hline $\begin{array}{l}\text { Es una asociación } \\
\text { autónoma de } \\
\text { personas que se han } \\
\text { unido } \\
\text { voluntariamente para } \\
\text { hacer frente a sus } \\
\text { necesidades y } \\
\text { aspiraciones } \\
\text { económicas, sociales } \\
\text { o culturales comunes } \\
\text { por medio de una } \\
\text { empresa de } \\
\text { propiedad conjunta y } \\
\text { democráticamente } \\
\text { controlada }\end{array}$ & $\begin{array}{l}\text { Las cooperativas de ahorro y crédito son cooperativas financieras democráticas propiedad de } \\
\text { los socios. Como intermediarios financieros, las cooperativas de ahorro y crédito financian } \\
\text { sus carteras de créditos movilizando los ahorros de los socios y los depósitos más que } \\
\text { empleando capital externo, con lo cual ofrecen oportunidades a muchas generaciones de } \\
\text { socios. Cada socio, sin importar el tamaño de su cuenta en la cooperativa de ahorro y crédito, } \\
\text { puede postularse para el consejo y emitir un voto en las elecciones. } \\
\text { Las cooperativas de ahorro y crédito existen para atender a sus socios y comunidades. Como } \\
\text { instituciones cooperativas sin fines de lucro, las cooperativas de ahorro y crédito emplean sus } \\
\text { ingresos excedentes para ofrecer a los socios créditos más accesibles, un mayor rendimiento } \\
\text { sobre sus ahorros, comisiones más bajas o nuevos productos y servicios. Atienden a los socios } \\
\text { de todos los niveles socioeconómicos, incluyendo los pobres y a todos aquéllos privados de } \\
\text { derechos. } \\
\text { Las cooperativas de ahorro y crédito son lugares seguros, prácticos, que permiten el acceso a } \\
\text { servicios financieros accesibles. Las cooperativas de ahorro y crédito ofrecen toda una gama } \\
\text { de servicios financieros, dando a los socios mayor flexibilidad para satisfacer sus necesidades } \\
\text { individuales. }\end{array}$ \\
\hline
\end{tabular}

Fuente: elaboración propia a partir de 1) González, Arias y San Bartolomé (2012), y 2 Organización de las Naciones Unidas para la Alimentación y la Agricultura - FAO (2019).

Respecto a la inclusión de componentes de Responsabilidad Social, García, Peñafiel, Troya y García (2017), plantean la gestión social cooperativa como el vínculo de ésta con la comunidad para lograr el beneficio colectivo, es decir, la gestión en base a principios de responsabilidad social (Luque, Ordóñez y Ruales, 2017). Contar con un presupuesto para la gestión social, no es suficiente sin la participación de los socios en el proceso de definición y aprobación de dicho presupuesto. Por tanto, los indicadores de gestión social son débiles al igual que la incentivación estatal de los mismos como elemento diferenciador del sector privado, diagnóstico que se repite frecuentemente en las entidades cooperativas financieras en el mundo. Si las razones expuestas no fueran suficientes, la definición de organización cooperativa lo deja claro al determinar que su objeto social es la intermediación financiera, comprometiendo a sus gestores al despliegue de los procesos de responsabilidad social en todas sus dimensiones. De acuerdo con Lindemann (2010: 50) "en los treinta años transcurridos entre 1975 y 2005, la contribución de los activos intangibles al valor global de las empresas había aumentado de un $17 \%$ a un $80 \%$ ". Para mostrar la integralidad de esta afirmación, en la Tabla 2, se presenta el desglose de las definiciones de cooperativa propuesta por Alianza Cooperativa Internacional -ACI- y de cooperativa de ahorro y crédito, propuesta por World Council of Credit Unions WOCCU- que por sí mismas, vinculan de forma directa a estas organizaciones con los principios y valores cooperativos y, por tanto, determinan la forma en que han de desarrollar su actividad económica (Degli y Portale, 2011). 


\section{Abordaje del problema}

El estudio de las cooperativas de ahorro y crédito adquiere un carácter multidimensional debido a la complejidad e interrelaciones que se generan en el sector teniendo presentes los elementos e intereses que gravitan alrededor de ellas. Con esta finalidad, se realiza un análisis comparativo de los indicadores financieros de las cooperativas de Ecuador en contraposición con los de la banca privada (Arias, 2003). El análisis del establecimiento de regulaciones diferenciadas entre bancos y cooperativas de ahorro y crédito se muestra necesario para conocer su taxonomía de incoherencias en base a sus balances, compromisos legales y éticos existentes (Bueno Campos, 1996). Se tiene presente que las investigaciones no suelen representar una solución definitiva al problema abordado, sino que, como ocurre en el presente caso, suelen ser una aproximación parcial que genera nuevos interrogantes que se convierten en el germen de otras investigaciones (Dorio, Sabariego y Massot, 2004).

El análisis realizado es mixto (cualitativo y cuantitativo). A nivel cualitativo de marcado carácter descriptivo al identificar el porqué de la similitud de parámetros a cumplir tanto por las COAC como por parte del sistema bancario tradicional a pesar de tener una idiosincrasia; y cuantitativo de corte longitudinal al analizar los datos de indicadores financieros y de gestión entre COAC y BP en el período 2015-2018. En su desarrollo se ponderan los datos recopilados de los organismos oficiales de manera lógica en base al análisis de cuatro años correspondientes al segmento 1, al ser este el de mayor volumen y tener en ocasiones estrategias similares al sector bancario, además de suponer el $77 \%$ de la cartera de crédito por segmento. De acuerdo la complejidad del objeto de estudio, de acuerdo a Peña y Pirela (2007), es posible construir un proceso para organizar y representar el conocimiento registrado originado, de hecho, Boza-Valle y ManjarezFuentes (2016), lo aplicaron en su estudio Diagnóstico estratégico de emprendimientos de economía popular y solidaria en Ecuador para describir de forma analítica y caracterizar documentos relacionados con el objeto de la investigación. Se examina la información a partir de 2015 donde la SEPS realiza la última clasificación de cooperativas de ahorro y crédito. Mediante este proceso, se propone determinar de forma comparada con los bancos privados de Ecuador, el crecimiento en activos, cartera bruta y resultados, así como el análisis de indicadores financieros y de gestión como el índice de morosidad, eficiencia microeconómica, tasa promedio activa y pasiva, resultados del ejercicio sobre el patrimonio promedio y resultados del ejercicio sobre activo promedio.

Además, se calcula el Índice de Herfindahl Hirschman o IHH, medida utilizada en los trabajos empíricos de sectores económicos teniendo en cuenta todos los puntos de la curva de concentración, en este caso se aplica tanto a las COAC como a la BP con la finalidad de medir el grado de concentración en los mercados financieros ecuatorianos. Es decir, el número de organizaciones que operan en los mismos y su capacidad de poder o control en ellos (Rhoades, 1993). Su cálculo se realiza utilizando la siguiente fórmula:

$$
I H H=\sum_{i=1}^{n} S_{i}^{2}
$$

Donde $s$ es la cuota de mercado expresada como un porcentaje de las COAC y BP enumeradas como $i$. Si el IHH es menor a 1.000 indica un mercado no concentrado. Si el índice IHH está entre 1.000 y 1.800 representa un mercado moderadamente concentrado y si los resultados muestran un IHH por encima de 1.800 indica un mercado altamente concentrado.

El ámbito competencia-estabilidad de mercado en organizaciones cooperativas es crucial a pesar de no haberse profundizado lo suficiente al centrarse los análisis en la BP salvo en contadas excepciones (Hesse y Cih’ak, 2007; Liu et al., 2012; Fiordelisi y Mare, 2014). De ahí la necesidad de conocer la concentración del mercado como un predictor más a tener en cuenta en este caso a través del IHH (Anexo 1 y 2). En las COAC analizadas asciende a 739,43 lo que implica la existencia de un mercado no concentrado (destacando la presencia de Juventud Ecuatoriana Progresista LTDA con un 20,24\% de activos), mientras que la BP asciende a 1.310,99 es decir, el sistema bancario tiene un mercado moderadamente concentrado (destacando la presencia del Banco pichincha con un 26,02\% de activos en el mercado). Autores como Flor (2013) y Barbecho y Puchi (2018), indican que el mercado ecuatoriano es moderadamente concentrado y de carácter monopolista respectivamente, siendo esto último contrario a los datos obtenidos. Una mayor presencia de COAC significa menos espacio para los bancos comerciales débiles en el mercado minorista (Barra y Zotti, 2019). En este caso, una mayor concentración de la BP evidencia una afectación a la estabilidad del mercado a pesar de tener presente que la evidencia empírica parece no ser concluyente (Mirzaei et al., 2013), debido a que existen resultados contradictorios en comparación con otros estudios académicos (Carletti y Hartmann 2003; Anginer et al., 2014). Sin embargo, una menor concentración del mercado podría comprometer la solvencia de algunas instituciones financieras debido entre otros motivos a su poco volumen de negocio y la falta de activos por cuenta corriente para operar. En otras palabras, en los mercados más concentrados los bancos podrán cobrar tasas de interés más altas, lo que aumentará el comportamiento de riesgo de los 
prestatarios, circunstancia replicada por las COAC en Ecuador emulando en ocasiones el ideario de la BP; además, las COAC al no conformar un volumen del mercado financiero su accionar no afecta de manera reseñable al resto del mercado financiero. Esto deja patente que su conducta es similar a una competencia oligopolista propia de un sistema de competencia imperfecta.

Es decir, el sistema financiero de cooperativas de Ecuador tiene bajo nivel de concentración desde el punto de vista de volumen de activos. Esto se debe a que es un mercado que no está supeditado a un único grupo de cooperativas a pesar de que la Cooperativa de Ahorro y Crédito Juventud Ecuatoriana Progresista (JEP) representa el 20,24\% del total de activos del sistema. Por otro lado, existe un mercado bancario levemente concentrado por tres entidades que son Banco Pichincha, Banco Pacífico y Produbanco. Esto se debe a que estos tres últimos representan el $51,15 \%$ del volumen de activos totales de casi una veintena de entidades bancarias que operan en el país andino.

\section{Análisis y resultados}

\subsection{Crecimiento en activos, cartera bruta y resultados}

El Catálogo Único de Cuentas - CUC (Superintendencia de Bancos, 2019), relaciona el marco legal de cumplimiento obligatorio para la intermediación financiera en Ecuador. Las cuentas contempladas corresponden a las que se han considerado necesarias para el registro de las operaciones que realizan las entidades detalladas en el Código Orgánico Monetario y Financiero y demás leyes y reglamentos pertinentes, controladas por la Superintendencia de Bancos y la Superintendencia de Economía Popular y Solidaria.

Según el CUC, los elementos relacionados directamente con la medida de la situación financiera en el balance de situación general, son los activos, los pasivos y el patrimonio neto mientras que los elementos relacionados con la medida del desempeño de resultados son los ingresos (dados por los intereses cobrados) y los gastos (en donde se consideran aquellos que se clasifican como gastos financieros es decir los intereses pagados y los gastos de explotación). En este contexto, los estados financieros que son construidos en función de estos lineamientos tienen una importante cantidad de cuentas. Sin embargo, ante el hecho de que los organismos de control determinan el tamaño de las instituciones financieras por sus activos, ésta es una cuenta de análisis obligatorio. El monto de cartera bruta (vigente, reestructurada, vencida y en cobro judicial sin incluir la provisión para créditos incobrables) se constituye en el principal activo de la intermediación financiera, representando el 66,64\% para los BP y el 75,56\% para las cooperativas respecto del activo total; de ahí que resulte interesante conocer el comportamiento de este proceso, máxime cuando es esta cuenta la que genera los ingresos en una institución financiera.

El monto de resultados que se obtiene es básicamente de restar los ingresos menos los gastos. Se relaciona de forma directa con el rendimiento de las instituciones, por lo que se incluye en el análisis para relacionarlo con el crecimiento de activos y otros indicadores que se calculan a partir de éste. El período considerado es entre $2015^{4}-2018$. Para efectos de mantener criterios comparativos, no se incluyen en el cálculo las instituciones financieras que han ingresado luego del año base, al segmento $1^{5}$ de cooperativas de ahorro y crédito (5) o al grupo de los bancos privados ${ }^{6}$ (2) en Ecuador.

En 2015, la SEPS organiza a las cooperativas de ahorro y crédito, en la actual segmentación según se explica en la Tabla 2.

Existen COAC que por el tamaño de sus activos pertenecen a otros segmentos. En 2018, la SEPS incluye en el segmento 1 a las cooperativas: Fernando Daquilema, Chibuleo Ltda., Ambato Ltda., 15 de Abril Ltda. y Construcción Comercio y Producción (orden según la cuenta de Activos).

6 De acuerdo a la legislación ecuatoriana, todos los bancos privados están bajo la supervisión de la SB. En 2016 se autoriza el funcionamiento de DINERS y VISIONFUND ECUADOR. 
Gráfico. 3. Crecimiento porcentual de Activos, Cartera Bruta y Resultados.

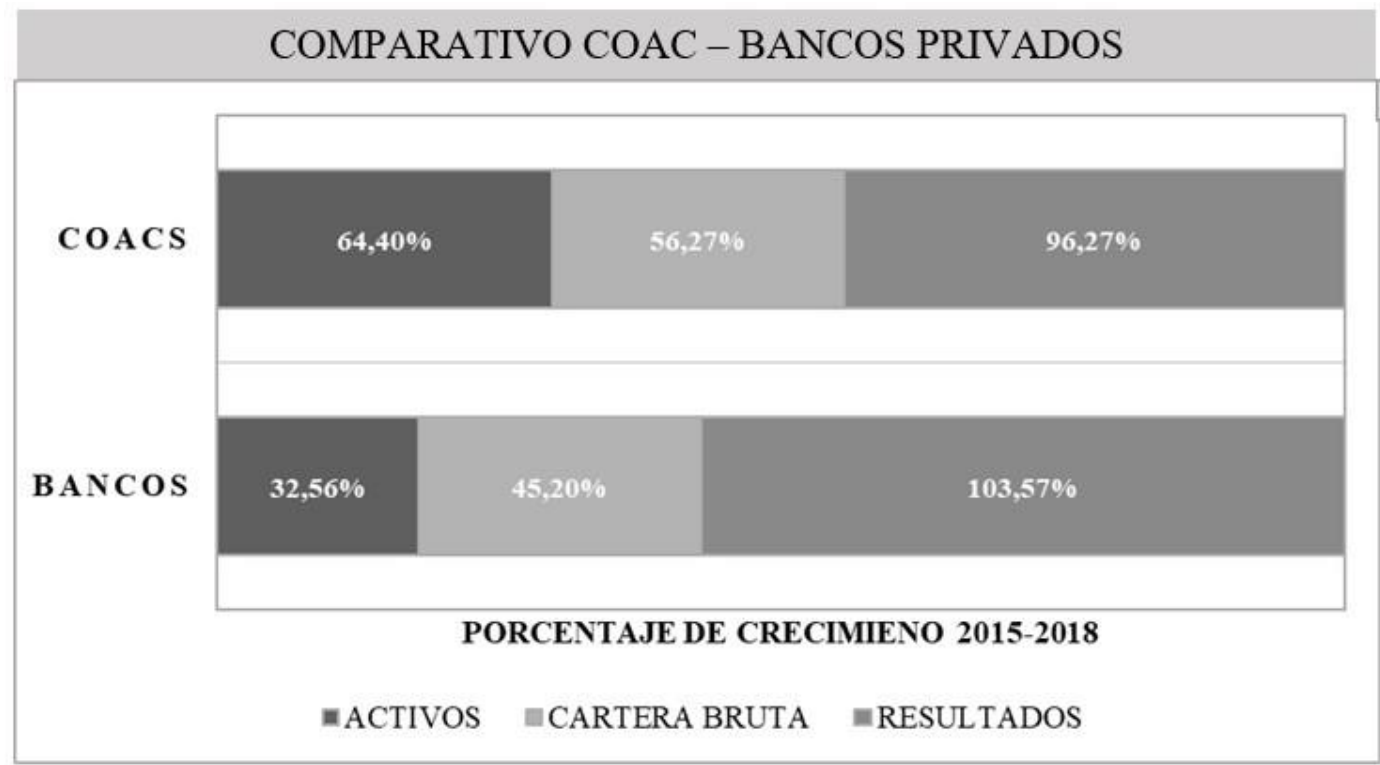

Fuente: elaboración propia a partir de información de Superintendencia de EPS (SEPS, 2018) y Superintendencia de Bancos (SB, 2018)

Las cooperativas de ahorro y crédito crecen en activos y cartera bruta en mayor porcentaje que los bancos privados. El crecimiento porcentual en activos representa el doble y en cartera bruta, aproximadamente un $25 \%$ más. En cuanto a los resultados del ejercicio, los bancos presentan un mayor crecimiento en al menos 7 puntos porcentuales sobre las COAC. En 2015 el sector cooperativo representaba el 14,99\% de los Activos del sistema financiero nacional ${ }^{7}$, en 2018 esta relación es del 17,99\% sin considerar las 5 cooperativas ingresadas recientemente ${ }^{8}$, es decir, su crecimiento ha sido más acelerado que el de los BP. El porcentaje en activos del sistema cooperativo en Ecuador es considerable teniendo en cuenta que en Brasil, el país más grande de América del Sur, en 2016 representa apenas el 10\% (Giusti, 2017). En el caso del resultado del ejercicio, existe un porcentaje de un 7,30\% mayor para los bancos privados sobre lo registrado por las COAC. Esto se debe principalmente al histórico de activos y a la diferencia que mantiene sobre los otros tipos de instituciones financieras y no a la diferencia entre las tasas activas y pasivas, como se puede verificar en el análisis de los indicadores financieros y de gestión (Ver Gráfico 3).

\subsection{Indicadores financieros y de gestión}

En Ecuador las instituciones financieras están obligadas a publicar entre otros indicadores, los de eficiencia por lo menos una vez al año con el fin de poner a disposición de accionistas, usuarios y público en general información económico-financiera que dictamine y refleje el desempeño de cada una de sus actividades, lo que consta en el Artículo 221 del Código Orgánico Monetario y Financiero (Asamblea Nacional de Ecuador, 2014). Los indicadores financieros permiten el análisis de las entidades para establecer la eficiencia originada en el negocio con relación al patrimonio promedio y al activo promedio a través del cálculo del ROE y ROA. Así también, es posible analizar la eficiencia operativa o de gestión para medir cuanto representan los gastos de operación en el margen neto financiero (Tenesaca, Villanueva, Malo y Higuerey, 2017). Con esta lógica normativa, se considera la revisión de algunos de los indicadores relacionados con el desempeño financiero y de gestión de cooperativas y bancos privados, de acuerdo a lo que se muestra en el Anexo 3, a partir de datos obtenidos y procesados por las superintendencias, excepto los numerados con 8 y 9 calculados para el presente estudio con el fin de contar con el spread financiero ${ }^{9}$ a partir de la determinación de tasas pasivas y activas promedio de BP y COAC. En el período de análisis se aprecia una variación en los porcentajes de todos los indicadores. Sin embargo, no existe relación entre el tipo de entidades. En ese sentido, el índice de morosidad en las cooperativas es mayor, comportamiento que responde a la tradición de los bancos a otorgar créditos de consumo con un riesgo financiero menor y por tener una cartera de productos más diversificada. Entre 2015 y 2018 la diferencia entre los registros de morosidad para BP y COAC desciende de $1,72 \%$ a $0,68 \%$, lo que indica un mejor control del indicador y

Para esta investigación se consideran en el Sistema Financiero de Ecuador a los BP y las COAC del segmento 1, instituciones que constituye más del $95 \%$ del total del Sistema.

Con la inclusión de las cooperativas ingresadas en 2018, las COAC representan el 18,82\%.

El spread es la diferencia entre el precio de compra y el precio de venta de un activo financiero. 
supone la inclusión de políticas y procesos para una colocación más efectiva por parte de las cooperativas de ahorro y crédito.

La Cobertura de la cartera con problemas, muestra una tendencia ascendente para los BP en todos los años de análisis. Cabe señalar un incremento en la diferencia entre tipo de institución pasando de 76,99\% a $103,22 \%$. Este indicador se recomienda que sea del 100\%. Las decisiones de incrementar sus montos se originan generalmente por causas técnicas descritas en tratados internacionales de manejo de intermediación financiera. La primera es la prudencia financiera; este es un principio contenido en los Acuerdos de Basilea III (2019) y se relaciona con los riesgos de crédito, operativo y de mercado.

Otra recomendación técnica para subir el porcentaje de cobertura de cartera es la administración de resultados del ejercicio, es decir, bajar o subir el monto de esta cuenta según las decisiones gerenciales o los requerimientos de mercado y de control. Resulta lógico que los BP tengan una mayor cobertura, pues tienen más activos y el capital en riesgo pertenece a un grupo minoritario de accionistas y en un momento de crisis pueden tomar de este rubro lo necesario para evitar cualquier impacto severo a su entidad y al sistema financiero. En el caso de las COAC, mantener un porcentaje tan alto (superior al 200\%) puede considerarse un síntoma de una débil administración que genera pérdida de oportunidades de negocio. La eficiencia microeconómica relaciona los gastos de operación con el margen financiero. En este caso, es superior para los BP en cada ejercicio económico del período analizado, con una diferencia de 5.39\% en 2015 y de 5,35\% en 2018, es decir, el porcentaje se mantiene incluso en la tendencia descendente del indicador, lo que advierte la optimización de recursos operativos en el sistema financiero en general.

La diferencia de 5 puntos porcentuales $(76,90 \%$ COAC y $71,55 \%$ BP en 2018), no coincide con la diferencia en activos. Por tanto, es posible afirmar que las cooperativas son menos eficientes desde el punto de vista operativo.

El ROE determina que los BP tienen un mejor Rendimiento sobre el Patrimonio mientras que las COAC tienen un mayor ROA. Por tanto, un mejor Rendimiento en relación con los Activos por parte de las cooperativas. Estos indicadores muestran la diferencia en la estructura financiera de las entidades y advierte que las cooperativas están generando mayores Resultados sobre los activos, de los cuales el $75 \%$ corresponde a Cartera Bruta de Crédito. El rendimiento de la cartera por vencer en su totalidad, muestra que el promedio de la tasa activa de las cooperativas, en todos los años del período de análisis, es mayor. En el año 2015, las COAC cobraban en promedio 4,22\% más en sus créditos que los BP, en 2018 esa diferencia sube a 5,04\%; es decir, que aunque la tendencia del indicador es descendente, crece la diferencia entre tipos de entidades. Este comportamiento supone al menos dos factores que se confirman con el análisis detallado de los balances: (1) el tipo de crédito de los BP es de consumo con tasa activa promedio menor que la de microcrédito que es atendida mayoritariamente por COAC; y, (2) las cooperativas tienen mayores gastos operativos y se muestran menos eficientes. Estos datos evidencian resultados que no se ajustan a la filosofía con que nacen las cooperativas de ahorro y crédito, confirmando que el sistema cooperativo en Ecuador, de manera endógena, prioriza la maximización económica utilizando los procesos de responsabilidad social de manera accesoria. Circunstancia apuntalada por la SEPS, ejerciendo más control de la parte financiera que de la social como se puede ver en las estadísticas publicadas en su propia página web. Todo ello unido a la perversión del propio concepto de responsabilidad social el cual pivota en un cúmulo de voluntariedades sin exigibilidades y a la confusión existente al ser establecidos dichos procesos a partir de acciones de filantropía, ayuda ${ }^{10}$, confraternidad, mecenazgo y patrocinios como por ejemplo el reparto de útiles de deporte, bolsas de caramelos y auspicios en fiestas populares. Aspectos que comprometen el cumplimiento del objeto social, misión o la aplicación de valores y principios del cooperativismo establecidos por antonomasia y en ocasiones puestos en segundo plano por parte de los socios en su legítimo control social, y en especial de quienes integran los organismos de gobierno. Aspecto trasladable a los Objetivos de Desarrollo Sostenible elaborados a partir de 17 objetivos para transformar nuestro mundo. De igual modo concentran 1) falta de una base teórica común, 2) falta de explicaciones sobre cómo lograr esos objetivos 3) características desiguales de los objetivos y 4) incompatibilidades o efectos indirectos negativos entre diferentes objetivos (Villalba, Egia y Pérez de Mendiguren, 2020).

La Liquidez es un indicador relevante para la intermediación financiera pues éste y el patrimonio dan muestra directa de la salud de las entidades y determinan la posibilidad de continuar operando o no con el público. En el período de análisis, en todas las lecturas la Liquidez es mayor para los BP, resultado propio de entidades que responden a accionistas que buscan mantener criterios de prudencia más estrictos en función de resguardar su inversión. En los Acuerdos de Basilea III, se recomienda que los niveles de liquidez sean suficientes y varíen de acuerdo al contexto; tradicionalmente está alrededor del $20 \%$, principalmente en las cooperativas; indicadores superiores pueden afectar la oportunidad de negocio en un entorno normal o favorable para la intermediación financiera debido a la falta de liquidez.

10 La Cooperativa de Ahorro y Crédito El Sagrario realiza hace tres años donativos a la Fundación Divina Misericordia para adultos mayores enfermos con cáncer, al igual que a la Fundación Cebicam de Guano para personas con discapacidad. Internamente la entidad tiene el voluntariado social y además practican el reciclaje [...] (SEPS, 2017). 
Respecto a los dos últimos indicadores del Anexo 3 (numerados con 8 y 9), el porcentaje de intereses generados se calcula a partir del monto de intereses ganados (cuenta 51) sobre el ingreso bruto (cuenta 5) y el porcentaje de intereses causados se obtiene del monto de los intereses causados (cuenta 41) dividido para las obligaciones con el público (cuenta 21). El cálculo es posible a partir de los estados financieros reportados por los organismos de control y se realiza con el fin de determinar el porcentaje promedio que las instituciones financieras, cobran por créditos y pagan por depósitos. El análisis de estos datos es primordial en el estudio para confirmar la orientación del modelo de gestión en las cooperativas de ahorro y crédito en Ecuador.

Gráfico. 4. Spread Financiero 2015 - 2016

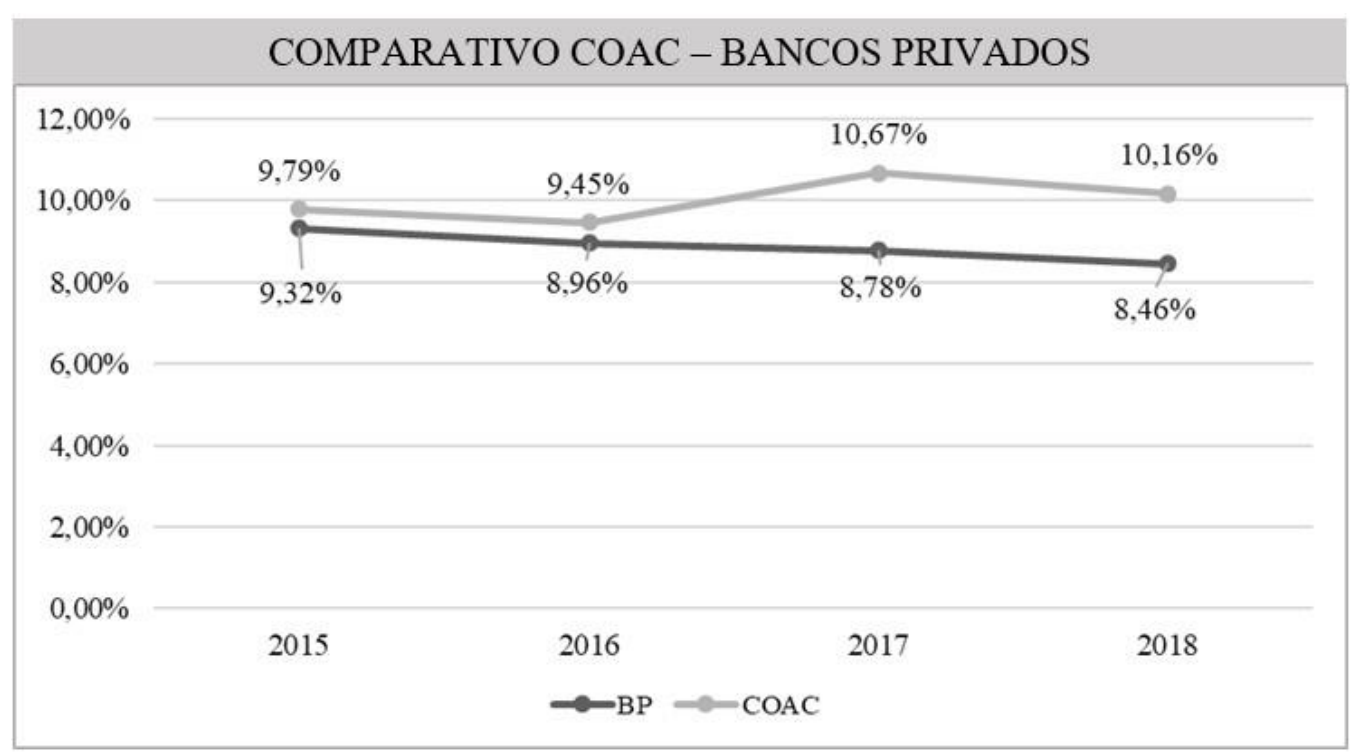

Fuente: elaboración propia a partir de los datos de la Tabla 4.

El análisis de la diferencia entre el porcentaje de intereses cobrados y pagados o spread financiero ${ }^{11}$ por tipo de entidad, muestra estabilidad en el período 2015-2018 (Gráfico 4). El porcentaje que las COAC perciben por los créditos otorgados, así como el porcentaje pagado por los depósitos, son porcentualmente el doble que lo recibido y pagado por los BP.

Las COAC muestran una tendencia ascendente del spread financiero contraria a lo que se registra para los BP y durante todo el período, es mayor para las cooperativas del segmento 1, sobre todo en el año 2018. El análisis se hace en puntos porcentuales y es posible establecer que las cooperativas de ahorro y crédito basan su gestión de intermediación financiera en estrategias de rendimiento financiero, lo que no responde a su naturaleza de ser una empresa de propiedad común, democráticamente contralada, que promueva los ahorros, sin fines de lucro y que incluya a los grupos vulnerables del entorno.

\section{Consideraciones finales}

Los más de diez años que han transcurrido desde el establecimiento de la actual Constitución en Ecuador no han sido suficientes para la instauración total de un sistema económico social y solidario. De hecho, su accionar se orienta de manera casi exclusiva a los procesos de economía popular y solidaria.

En este escenario, las cooperativas de ahorro y crédito han crecido en volumen de negocio más que los bancos pero en lugar de plantear estrategias que les permitan ser reconocidas como líderes en la gestión social y solidaria, de manera continua implementan maniobras de intermediación financiera a partir de la réplica al sector bancario privado ofreciendo como ejemplo altos tipos de interés a sus activos y disponer de menores ratios de endeudamiento, circunstancia que conlleva un menor aporte de liquidez al sistema que el realizado por el sector bancario privado con más activos a la vez que una mayor deuda como demuestran sus balances. Tales circunstancias, alejan a las COAC del cumplimiento de criterios de responsabilidad social y de identidad cooperativa; aspectos que deberían ser intrínsecos a su gestión, de ahí que las cooperativas sean menos eficientes y menos éticas al fomentar un spread más elevado en comparación con los bancos privados

11 Spread financiero que es la diferencia entre el precio de compra y el de venta de un activo financiero. Para el cálculo se resta el porcentaje de interés causado menos el porcentaje de interés pagado por las entidades financieras. 
de Ecuador. Circunstancia alejada de su naturaleza por tanto su gestión no se ajusta al concepto formulado por la Alianza Cooperativa Internacional -ACI- y el Consejo Mundial de Cooperativas de Ahorro y Crédito WOCCU- y mucho menos al carácter social esperado. La legislación común para bancos y cooperativas en Ecuador no permite la diferenciación, más bien se generan mayores riesgos ya que adicionalmente a los de crédito, mercado y operativo, se suma el riesgo reputacional generado por los problemas de (mal) gobierno que se presentan con relativa frecuencia en las cooperativas. A pesar de que las COAC operan en un mercado no concentrado y por tanto con menor irradiación de competencia imperfecta como evidencia el IHH, estas cooperativas desarrollan una actividad en plena armonía y sin voces discordantes, de ahí que tanto por acción como por omisión en ocasiones su actividad pueda estar mimetizada con la BP cuando su propuesta debería ser precisamente la de ser una propuesta alternativa a los mismos.

Se deja abierta la puerta al establecimiento de una normativa especializada que garantice la sostenibilidad y el compromiso social en las cooperativas de ahorro y crédito como tarea pendiente del Estado a través del mandato constitucional fomentando así una verdadera herramienta social y no una mera estructura de marketing institucional.

\section{Referencias bibliográficas}

Acosta, A. (2010) El Buen Vivir en el camino del post-desarrollo: Una lectura desde la Constitución de Montecristi. Friedrich-Ebert-Stiftung-ILDIS. Policy Paper 9.

Alianza Cooperativa Internacional. (2018) Cooperativas. Obtenido de https://www.ica.coop/es/cooperativas/que-esuna-cooperativa.

Anginer D., Demirguc-Kunt A. y ZHU M. (2014) How does bank competition affect bank systemic risk? Journal of Financial Intermediation, $\mathrm{N}^{\circ} 23$, pp. 1-26.

Arias, M. (2003) Metodologías de investigación emergentes en economía de la empresa. Bordeaux: Papers Proceedings 2003, XVII Congreso Nacional XIII congreso hispano-francés AEDEM,Université Montesquieu Bordeaux IV.

Asamblea Constituyente. (1998) Constitución de la República de Ecuador 1998. Quito: Asamblea Constituyente.

Asamblea Constituyente. (2008) Constitución de la Républica de Ecuador 2008. Quito: Asamblea Constituyente.

Asamblea Nacional de Ecuador. (2014) Código Orgánico Monetario y Financiero. Quito: Registro Oficial 332.

Asociación Nacional de Cooperativas de Ahorro y Crédito controladas por la SBS. (2010) Guía metodológica para la introducción de la Responsabilidad social y del Balance Social en Cooperativas de Ahorro y Crédito. Quito: Conferación Alemana de Cooperativas - DGRV.

Barbecho, K. y Puchi, M. (2018) Competencia y estabilidad en el sistema bancario: Evidencia empírica para el Ecuador durante el periodo 2001-2016. Universidad de Cuenca, Ecuador. Obtenido de http://dspace.ucuenca.edu.ec/handle/123456789/30712.

Barra, C. y Zotti, R. (2019) Bank performance, financial stability and market concentration: evidence from cooperative and non-cooperative banks. Annals of Public and Cooperative Economics, 90(1), pp. 103-139.

Bastidas-Delgado, O. (2007) La autogestión como innovación social en las cooperativas. Venezuela: Red Universitaria de las Américas en Estudios Cooperativos y Asociativismo (RED Unircoop).

Bauman, Z. y Bordoni, C. (2016) Estado de Crisis. Barcelona: Paidos Ibérica.

Birchall, J. (2004). Cooperatives and the millennium development goals. Cooperative Branch \& Policy Integration Department International Labour Office, Geneva Committee for the Promotion and Advancement of Cooperatives. Obtenido de https://community-wealth.org/sites/clone.community-wealth.org/files/downloads/book-birchall.pdf.

Boza-Valle, J. y Manjarez-Fuentes, N. (2016) Diagnóstico estratégico de emprendimientos de economía popular y solidaria en ecuador. Ingeniería Industrial, 37(2), La Habana mayo-ago. pp. 208-217.

Bueno Campos, E. (1996) Dirección Estratégica de la Empresa. Metodologías, técnicas y casos. Madrid: Pirámide.

Carletti E. y Hartmann P. (2003) Competition and financial stability: What's special about banking? in P. Mizen (ed.), Monetary History, Exchange Rates and Financial Markets: Essays in Honour of Charles Goodhart, Vol. 2, Cheltenham, UK: Edward Elgar.

Chauveau, D., Alderete, F., Carrasco, K., Hernández, L. y Linsambarth, R. (2010) Modelos cooperativos para el acceso a Internet en sectores rurales. Santiago: Fundación para la Innovación Agraria.

Comité de Supervisión Bancaria de Basilea. (2019) Resumen de las Reformas de Basilea III. Obtenido de https://www.bis.org/bcbs/publ/d424 hlsummary es.pdf.

Coque, J. (2005) Compartir Soluciones: Las cooperativas como factor de desarrollo en las zonas desfavorecidas. Madrid: Consejo Económico y Social.

Coraggio, J. (2013) La onstrucción de otra economía como acciónpolítica. En S. d. Solidaia, Estudios sobre Economía Popular y solidaria, pp. 15-48. Quito: V\&M Gráficas.

Da Ros, G. (2007) El movimiento cooperativo en el Ecuador. Visión histórica, situación actual y perspectivas. CIRIECEspaña, Revista de Economía Pública, Social y Cooperativa, № 57, pp. 249-284

Degli, G. y Portale, E. (2011) The effect of corporate social responsibility on social capital creation in social cooperatives. Nonprofit and Voluntary Sector Quarterly, 40(3), pp. 566-582.

Dorio, I., Sabariego, M. y Massot, I. (2004) Características generales de la metodología cualitativa. Madrid: Metodología de la investigación educativa, 277-292. 
Elizondo, L. (2015) La Economía Social y Solidaria en Ecuador: Material de Lectura. Bilbao: Hegoa.

Estévez-Torres, Z; Clivillé, A. (2019) Problemas que afectan el desempeño del sistema financiero ecuatoriano en el siglo XXI, Revista Caribeña de Ciencias Sociales, 4. En línea https://www.eumed.net/rev/caribe/2019/04/sistemafinanciero-ecuador.html.

Evans, M. y Syrett, S. (2007) Generating social capital? The social economy and local economic development. European Urban and Regional Studies, 14(1), pp. 55-74.

Fernández, L., Geba, N., Montes, V. y Schaposnik, C. (1998) Balance Social cooperativo integral. Cuaderno Serie de Investigación, $\mathrm{N}^{\circ} 57$. Obtenido de:

http://sedici.unlp.edu.ar/bitstream/handle/10915/43955/Documentocompleto.pdf?sequence=1\&isAllowed=y.

Fiordelisi F. y Mare D. S. (2014) Competition and financial stability in European cooperative banks. Journal of International Money and Finance, $\mathrm{N}^{\circ} 45$, pp. 1-16.

Flor, G. (2013) Análisis de concentración, poder demercado y de la incidencia de la regulacion de tasasde interes en los productos de credito del sector bancario ecuatoriano en el periodo 2003-2011. Pontificia Universidad Católica del Ecuador. Obtenido de http://repositorio.puce.edu.ec/handle/22000/6871.

García, A., Peñafiel, J., Troya, Y. y García, J. (2017) La actividad social en cuatro Cooperativas de Ahorro y Crédito de Pichincha, Ecuador. Cooperativismo y Desarrollo, 5(2). COODES, pp. 97-107. Obtenido de http://coodes.upr.edu.cu/index.php/coodes/article/view/155.

González, L., Arias, N. y San Bartolomé, J. (2012) El balance social cooperativo: Una herramienta necesaria para la gestión cooperativa. ACIAméricas, Ed. Jornadas 2012, Propuestas del cooperativismo. Rosario, Argentina.

Giusti, S. (2017) La experiencia brasileña en la integración del sector cooperativo. En S. d. Soliaria, La Integración, cave para el éxito de los actores de la Economía Popular y Solidaria. Quito: LHG Studio, pp. 121-140.

Guerra, P. (2014) La construcción de una socioeconomía solidaria cómo un fenómeno comunitarista: el caso latinoaméricanp. En S. d. Solidaria, Contextos de la otra economía. Quito: Imprenta Calderón, pp. 11-24.

Guridi, L. y Jubeto, Y. (2014) Fundamentos conceptuales y principios de la Economía Social y Solidaria. En Y. Jubeto, L. Guridi y M. Fernández-Villa, Diálogos sobre la Economía Social y Solidaria. Encuentros y desencuentros con las propuestas para otras economías. Bilbao: Hegoa, pp. 17-58.

Harvey, D. (2007). Breve historia del neoliberalismo. Madrid: Akal.

Hernández Zubizarreta, J. y Ramino, P. (2016) Contra la Lex Mercatoria. Barcelona: Icaria.

Hesse H. and Ciha'k M. (2007) Cooperative banks and financial stability, IMFWorking Paper No. 07/02.

Íñigo, L. (2012) La breve historia de la revolución industrial. Madrid: Nowtilus.

Jácome, H. (2019) Superintendencia de Economía Popular y Solidaria. Obtenido de Presentaciones: http://www.seps.gob.ec/interna-npe?11402.

León, M. (2009) Cambiar la Economía para cambiar la Vida. En A. Acosta, A. y Martínez, E. El Buen Vivir. Quito: Abya-Yala, pp. 1-6.

Lindemann, J. (2010) El valor financiero de la marca. Madrid: LID, 48-65.

Liu H., Molyneux P. y Wilson J. O. S. (2012) Competition and stability in European banking: a regional analysis. Manchester School, № 81, pp. 176-201.

Loor, I., González, F., Moreira, N. y Hidalgo-Fernández, A. (2020) Study of Corporate Sustainability Dimensions in the Cooperatives of Ecuador. Sustainability, 12(2), 462.

Lucas, A., García, P. y Llano, S. (2002) Historia Social de las Organizaciones. En A. Lucas, Sociología de las Organizaciones, Madrid: Fragua, pp. 25-120.

Lucena, H., Freitez, N. y Hernández, A. (2007) Cooperativas, Empresas, Estado y Sindicatos. Una vinculación necesaria. Universidad de Carabobo y Universidad Centroccidental Lisandro Alvarado. Venezuela: Barquisimeto

Luque, A. y Casado, F. (2020) Public Strategy and Eco-Social Engagement in Latin American States: An Analysis of Complex Networks Arising from Their Constitutions, 12 (20), pp. 1-29. https://doi.org/10.3390/su12208558.

Luque, A. y Herrero-García, N. (2019) How corporate social (ir)responsibility in the textile sector is defined, and its impact on ethical sustainability: An analysis of 133 concepts. Corporate Social Responsibility and Environmental Management, may, pp. 1-22. https://doi.org/10.1002/csr.1747.

Luque, A., Peñaherrera, J. y Ordoñez, J. (2019) Comparación de los resultados del balance social como herramienta de gestión: los casos de CACEC y Chibuleo. Chakiñan, Revista de Ciencias Sociales y Humanidades, № 7, pp. 104117.

Luque, A., Herrero-García, N. y Peñaherrera, J. (2018) Extractivismo en América Latina: ¿bien común o democracia delegativa? Revista Electrónica de Medioambiente, Universidad Complutense de Madrid, Vol. 19(1), pp. 121-137.

Luque, A., Ordóñez, J. y Ruales, V. (2017) La responsabilidad social en las asociaciones de la Economía Popular y Solidaria. II Congreso Internacional sobre Ciencia, Sociedad e Investigación Universitaria. 18 octubre de 2017, Ambato (Ecuador). ISSN: 2550-679X. Obtenido de: http://repositorio.pucesa.edu.ec/bitstream/123456789/2223/1/RS.pdf.

Mankiw, G. y Taylor, M. (2017) Economía. Asturias: Paraninfo.

Martín-Mayoral, F. (2009) Estado y mercado en la historia de Ecuador: Desde los años 50 hasta el gobierno de Rafael Correa. Nueva Sociedad, № 221, 120.

Mathiyazhagan, K., Govindan, K., NoorulHaq, A. y Geng, Y. (2013) An ISM approach for the barrier analysis in implementing green supply chain management. Journal of Cleaner Production, N ${ }^{\circ}$ 47, pp. $283-297$. https://doi.org/10.1016/j.jclepro.2012.10.042. 
Mirzaei A., Moore T. y Liu G. (2013) Does market structure matter on banks' profitability and stability? Emerging vs. advanced economies. Journal of Banking and Finance, $\mathrm{N}^{\circ} 37$, pp. 2920-2937.

Moulaert, F. y Ailenei, O. (2005) Social economy, third sector and solidarity relations: A conceptual synthesis from history to present. Urban studies, 42(11), pp. 2037-2053.

Organización de las Naciones Unidas para la Alimentación y la Agricultura - FAO. (2019) Agronoticias. Obtenido de Las cooperativas de ahorro y crédito en América Latina: http://www.fao.org/inaction/agronoticias/detail/es/c/510609/.

Passet, R. (2013) Las grandes representaciones del mundo y la economía a lo largo de la historia : del universo mágico al torbellino creador. Madrid: Clave intelectual.

Peña, T. y Pirela, J. (2007) La complejidad del análisis documental. Información, Cultura y Sociedad. No. 16. Buenos Aires: Universidad de Buenos Aires. Facultad de Filosofía y Letras. Instituto de Investigaciones. pp. 55-81.

Pérez de Mendiguren, J. y Etxezarreta, E. (2015) Sobre el concepto de economía social y solidaria: Aproximaciones desde Europa y América Latina. Revista de Economía Mundial, pp. 123-144.

Polo-Blanco, J. (2019) Capitalismo, derecho y libertad nunca fueronexacamente la misma cosa. Reflexiones en torno a una cuestión moderna y contemporánea. Revista de Humanidades, 9(1), pp. 1-22.

Razeto, L. (2010) ¿Qué es la economía solidaria? Revista Papeles de Relaciones Ecosociales y Cambio Global, № 110 , pp. 47-52.

Rhoades, S. A. (1993) The herfindahl-hirschman index. Fed. Res. Bull., N $^{\mathrm{o}}$ 79, p. 188 . Obtenido de https://heinonline.org/HOL/LandingPage?handle=hein.journals/fedred79\&div=37\&id=\&page=.

Sánchez Barrilao, J. (2004) Sobre la constitución normativa y la globalización, Revista de la Facultad de Derecho de la Universidad de Granada, № 7, pp. 241-261.

SB. (2018) Superintendencia de Bancos. Portal Estadistico. Obtenido de Servicios Financieros: http://estadisticas.superbancos.gob.ec/portalestadistico/portalestudios/?page id=1826.

SB. (2019) Superintendencia de Bancos. Obtenido de Catálogo de Cuentas: https://www.superbancos.gob.ec/bancos/catalogo-de-cuentas/.

Schlusberg, M. (1969) Corporate legitimacy and social responsibility: The role of law. California Management Review, 12(1), pp. 65-76.

SEPS. (2017) Cooperativas hacia la responsabilidad social,. Obtenido de https://www.seps.gob.ec/noticiamedio?cooperativas-hacia-la-responsabilidad-social.

SEPS. (2018) Boletines Financieros Mensuales. Obtenido de Boletines Financieros Segmento 1: Boletines Financieros Segmento 1. Obtenido de http://www.seps.gob.ec/estadistica?boletines-financieros-mensuales.

SEPS. (2019) Consulta de Organizaciones. Obtenido de https://servicios.seps.gob.ec/gosfinternet/paginas/consultarOrganizaciones.jsf.

SEPS. (2020) El 50\% de las operaciones de crédito han sido refinanciadas en el Sector Financiero de la EPS. Obtenido de https://www.seps.gob.ec/noticia?el-50-de-las-operaciones-de-credito-han-sido-refinanciadas-en-el-sectorfinanciero-de-la-eps.

Solón, P. (2020) El Buen Vivir: cosmovisiones ancestrales y nuevos paradigmas. Obtenido de El Salto diario: https://www.elsaltodiario.com/guerrilla-translation/el-buen-vivir-cosmovisiones-ancestrales-y-nuevos-paradigmas.

Tenesaca, K., Villanueva, J., Malo, Z. y Higuerey, A. (2017) Sistema bancario de Ecuador: una aproximación a sus indicadores de estabilidad y eficiencia. Publicando, pp. 255-279.

UNESCO. (2018) Robert Owen. Oficina Internacional de Educación, $1999 . \quad$ Obtenido de http://www.ibe.unesco.org/sites/default/files/owens.pdf.

Villalba, U., Egia, A. y Pérez de Mendiguren, J. C. (2020) Convergences between the Social and Solidarity Economy and Sustainable Development Goals: Case Study in the Basque Country. Sustainability, 12(13), 5435. 
7. Anexos

Anexo 1

Cooperativas de Ahorro y Crédito - Segmento 1

\begin{tabular}{|c|c|c|c|}
\hline \multirow{2}{*}{ ENTIDADES } & \multicolumn{2}{|c|}{ Activos (12/2018) } & \multirow{2}{*}{$\begin{array}{c}\text { Índice } \\
\text { Herfindahl } \\
\text { Hirschman }\end{array}$} \\
\hline & Dólares & Porcentaje & \\
\hline Juventud Ecuatoriana Progresista LTDA & $1.919 .745 .061,04$ & $20,24 \%$ & 409,66 \\
\hline Jardín Azuayo LTDA & $857.441 .902,50$ & $9,04 \%$ & 81,72 \\
\hline Policía Nacional LTDA & $773.424 .593,96$ & $8,15 \%$ & 66,42 \\
\hline Cooprogreso LTDA & $502.877 .256,92$ & $5,30 \%$ & 28,09 \\
\hline 29 De Octubre LTDA & $492.720 .652,97$ & $5,19 \%$ & 26,94 \\
\hline Oscus LTDA & $373.253 .867,10$ & $3,93 \%$ & 15,44 \\
\hline San Francisco LTDA & $330.390 .740,64$ & $3,48 \%$ & 12,11 \\
\hline Alianza Del Valle LTDA & $309.910 .570,55$ & $3,27 \%$ & 10,69 \\
\hline Riobamba LTDA & $306.472 .018,49$ & $3,23 \%$ & 10,43 \\
\hline De La Pequeña Empresa de Cotopaxi LTDA & $304.148 .805,78$ & $3,21 \%$ & 10,30 \\
\hline Vicentina Manuel Esteban Godoy Ortega LTDA & $290.988 .765,77$ & $3,07 \%$ & 9,42 \\
\hline Andalucía LTDA & $256.108 .816,31$ & $2,70 \%$ & 7,29 \\
\hline De La Pequeña Empresa Biblian LTDA & $229.677 .185,75$ & $2,42 \%$ & 5,86 \\
\hline Mushuc Runa LTDA & $225.533 .627,85$ & $2,38 \%$ & 5,66 \\
\hline Tulcan LTDA & $198.596 .986,15$ & $2,09 \%$ & 4,37 \\
\hline El Sagrario LTDA & $186.860 .232,93$ & $1,97 \%$ & 3,88 \\
\hline Atuntaqui LTDA & $185.549 .184,33$ & $1,96 \%$ & 3,84 \\
\hline 23 de Julio LTDA & $179.156 .885,23$ & $1,89 \%$ & 3,57 \\
\hline Pablo Muñoz Vega LTDA & 176.583.411,57 & $1,86 \%$ & 3,46 \\
\hline Cámara De Comercio De Ambato LTDA & $152.754 .239,51$ & $1,61 \%$ & 2,59 \\
\hline San Jose LTDA & $152.522 .611,14$ & $1,61 \%$ & 2,59 \\
\hline $\begin{array}{l}\text { De Los Servidores Públicos Del Min. De Educación y } \\
\text { Cultura }\end{array}$ & $151.045 .396,73$ & $1,59 \%$ & 2,53 \\
\hline De La Pequeña Empresa de Pastaza LTDA & $138.709 .112,61$ & $1,46 \%$ & 2,13 \\
\hline Fernando Daquilema & $138.522 .911,32$ & $1,46 \%$ & 2,13 \\
\hline Chibuleo LTDA & 134.180.487,09 & $1,41 \%$ & 1,99 \\
\hline Pilahuin TIO LTDA & $128.934 .371,88$ & $1,36 \%$ & 1,85 \\
\hline Santa Rosa LTDA & $123.290 .395,63$ & $1,30 \%$ & 1,69 \\
\hline Ambato LTDA & $110.578 .244,97$ & $1,17 \%$ & 1,37 \\
\hline 15 De Abril LTDA & $83.116 .661,52$ & $0,88 \%$ & 0,77 \\
\hline Construcción Comercio Y Producción LTDA & $73.965 .209,86$ & $0,78 \%$ & 0,61 \\
\hline TOTAL SEGMENTO I & $9.487 .060 .208,10$ & $100,00 \%$ & $\mathbf{7 3 9 , 4 3}$ \\
\hline
\end{tabular}

Fuente: elaboración propia a partir de información de la Superintendencia de EPS (SEPS, 2018) 


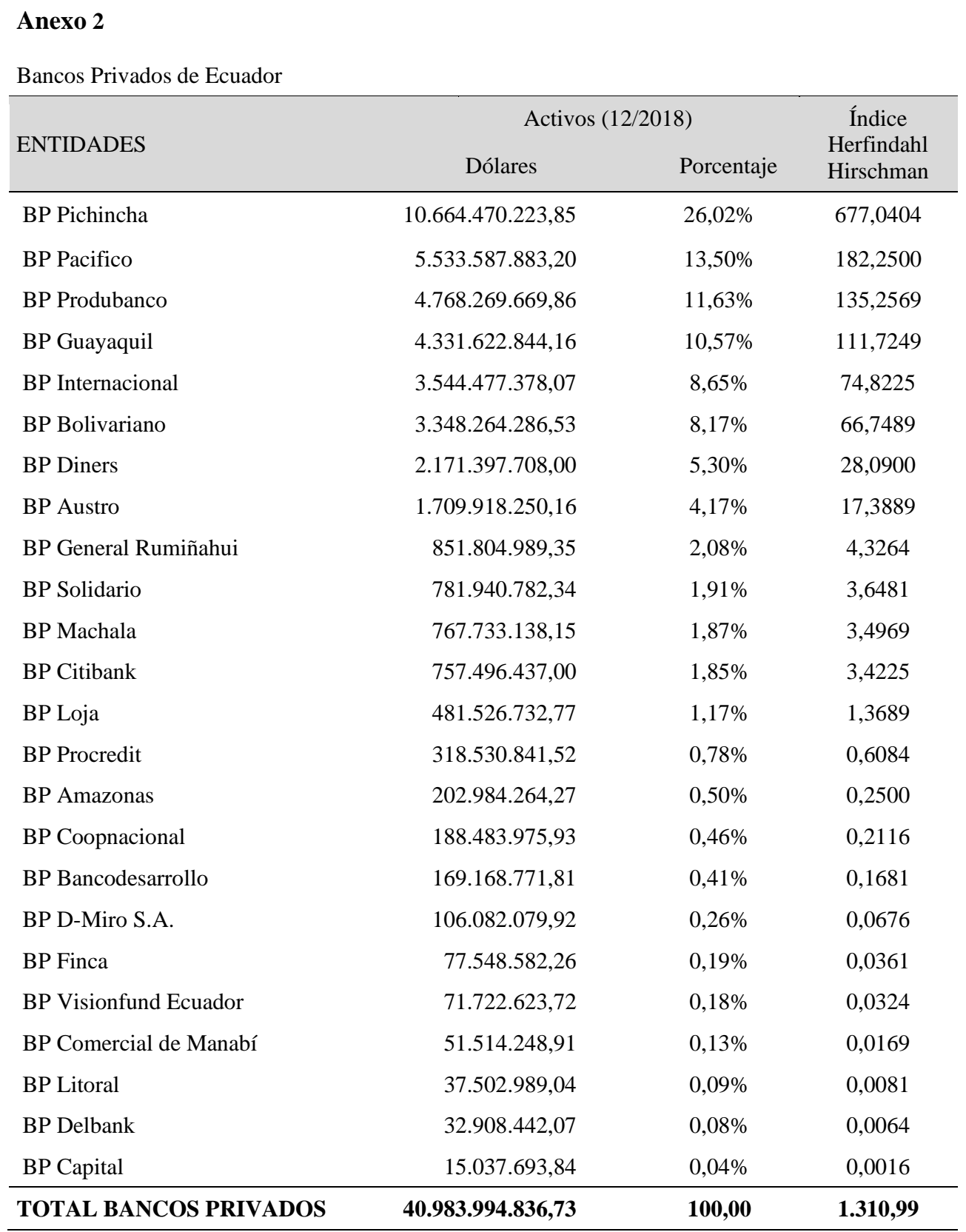

